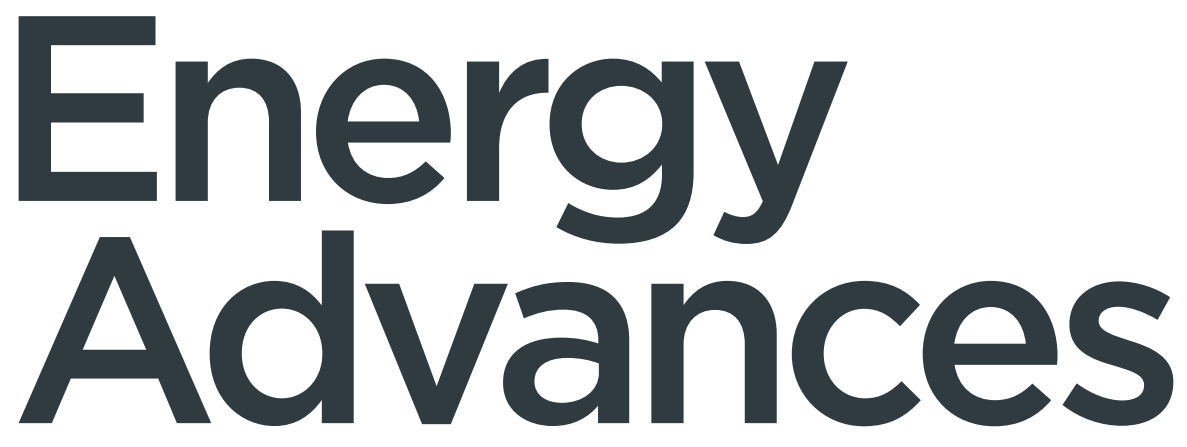

Volume 1

Number 3

March 2022

Pages 131-178

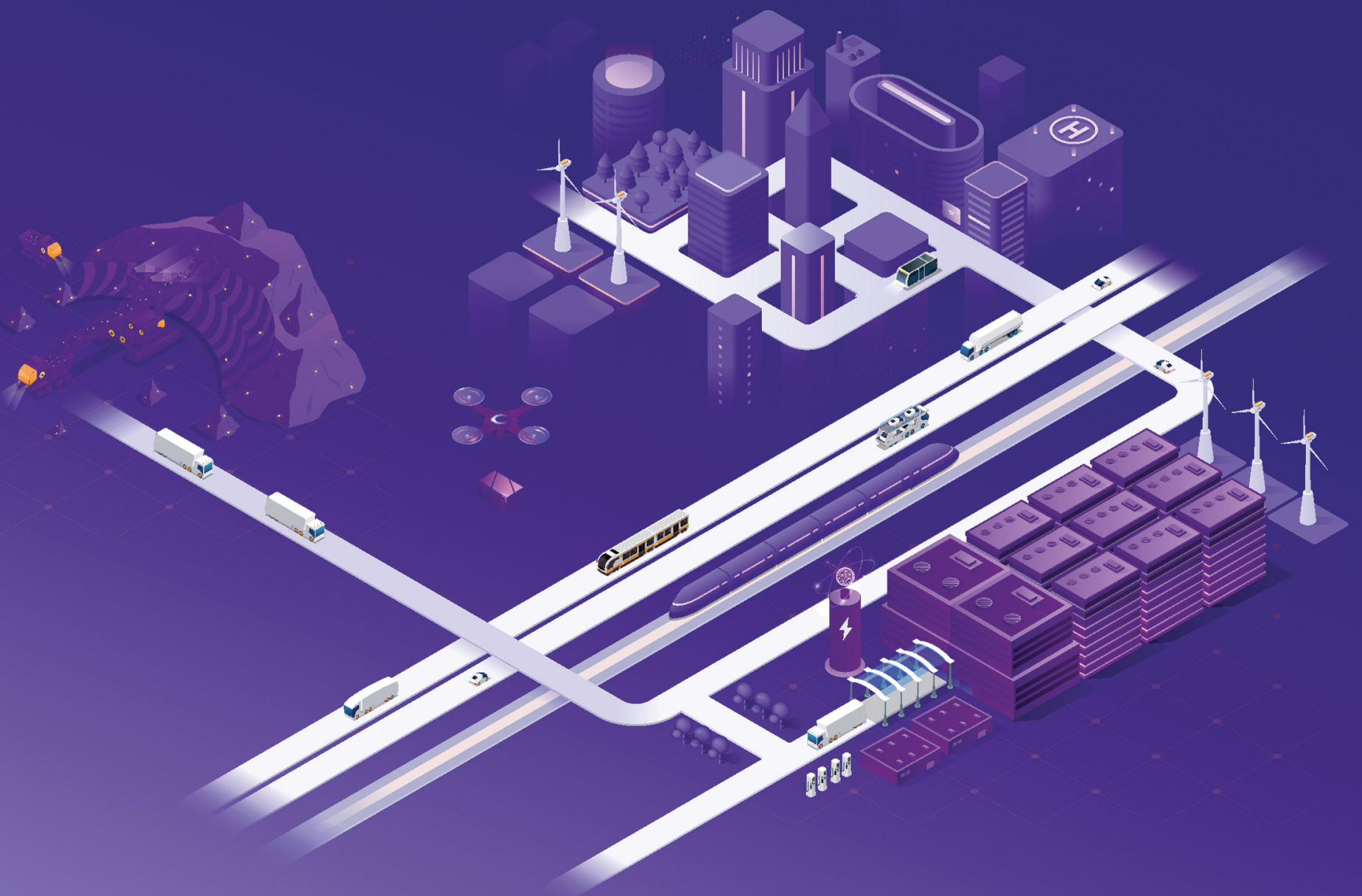

ISSN 2753-1457

ROYAL SOCIETY OF CHEMISTRY

\section{PAPER}

Lukas Mauler et al.

Technological innovation vs. tightening raw material

markets: falling battery costs put at risk 


\section{Check for updates}

Cite this: Energy Adv., 2022, 1, 136

Received 11th November 2021 Accepted 21st January 2022

DOI: $10.1039 /$ d1ya00052g

rsc.li/energy-advances

\title{
Technological innovation vs. tightening raw material markets: falling battery costs put at risk $\dagger$
}

\author{
Lukas Mauler, (D) *ab Xixue Lou, (D) ${ }^{a}$ Fabian Duffner ${ }^{\mathrm{ab}}$ and Jens Leker ${ }^{\mathrm{ac}}$
}

\begin{abstract}
The reduction of battery costs is a key enabler for an economically viable transition towards a climateneutral society. Despite market analysts being concerned about rising raw material prices, across forecasting studies, battery costs are expected to decline in the future. Respective authors base their cost estimates on past material price developments and do not rely on explicit technology roadmaps. This study integrates both future material price expectations and cost reductions driven by technological innovation. Therefore, a roadmap is defined for automotive battery technology and its production process throughout 2030, based on market expectations and expert knowledge. This roadmap is translated into year-over-year cell cost by two engineering-based, bottom-up material and process cost models and, at current raw material prices, a decline from above 100 to around $70 \$ \mathrm{~kW} \mathrm{~h}^{-1}$ in 2030 is forecasted. The simulation of analysts' price expectations for critical materials reveals that this decline might significantly flatten or, in the most pessimistic case, vanish completely. A particularly high risk for cell cost is associated with the nickel price and consequently, implications for research and industry are outlined for its mitigation.
\end{abstract}

\section{Broader context}

The road transportation sector accounts for approximately one fifth of global greenhouse gas emissions and the aim of its decarbonization has become the focus of policy measures. In particular for passenger vehicles, industry has reacted by bringing battery-powered electric vehicles to the market in order to replace internal combustion engines that burn fossil fuels for vehicle traction. While these vehicles operate emission-free at point of use and represent a lowcarbon alternative if electricity is supplied by renewable energy sources, their current purchase price is not fully competitive to conventional cars. For an affordable and economically viable mobility transition, industry strives for cost reductions and the battery, the single most costly component of an electric vehicle, has taken center stage in these efforts. Significant cost reductions have been achieved in the last decade and research in academia and industry has brought forward promising technological measures aiming to further reduce battery material and production cost in the future. However, the battery demand from the ongoing global policy-driven electric vehicle ramp-up is putting strain on upstream material markets that might not be able to extend supply at a similar pace, resulting in increased material prices and, in turn, having an increasing effect on battery cost. This study analyzes these opposing effects by identifying relevant innovations in battery technology and its production process, integrating material market developments, and sheds light on their combined impact on future battery cost.

\section{Introduction}

Batteries are taking center stage in the transition of the mobility sector towards climate-neutrality, ${ }^{1}$ since they represent a locally $\mathrm{CO}_{2}$ free alternative to fossil fuels in vehicles, ${ }^{2,3}$ and can mitigate the generation variability of renewable energy sources in electricity supply. ${ }^{4}$ The cost of lithium-ion batteries (LIB), the state-of-the-art

\footnotetext{
${ }^{a}$ Institute of Business Administration at the Department of Chemistry and Pharmacy, University of Münster, Münster, Germany

E-mail:lmauler@uni-muenster.de

${ }^{b}$ Porsche Consulting GmbH, Bietigheim-Bissingen, Germany

${ }^{c}$ Helmholtz Institute Münster, IEK-12, Forschungszentrum Jülich GmbH,

Münster, Germany
}

$\dagger$ Electronic supplementary information (ESI) available. See DOI: 10.1039/d1ya00052g technology in electric vehicles ${ }^{5,6}$ and economically promising in stationary energy storage applications, ${ }^{7}$ is considered too high to render battery-powered products fully competitive with their conventional counterparts, ${ }^{8}$ even though it has decreased more than fivefold during the past decade. ${ }^{9}$ On the one hand, this trend is expected to further continue in the future, as shown by a recent review of battery cost forecasting studies that use the methods of technological learning, literature-based projection, bottom-up modeling, and expert elicitation. ${ }^{10}$ Major drivers of these expectations are technological advances in both, battery technology and its production process, ${ }^{11}$ and economies of scale by a global expansion of LIB production. ${ }^{12,13}$ On the other hand, industry analysts are increasingly concerned about rising prices for critical raw materials ${ }^{14,15}$ as demand expectations are growing significantly 
and currently committed investments for future mining activities are considered insufficient. ${ }^{16,17}$ To date, battery cost forecasting studies do not rely their estimates on explicit technology roadmaps and neglect the effect of future raw material price expectations, thus impeding an evaluation of the combined effect of technological innovations and tightening raw material markets on future battery cost. This study attempts to close this gap by applying a new multistep, engineering-based modeling method, an approach considered to be required to further evaluate future battery cost development, ${ }^{18}$ in order to derive cost forecasts throughout 2030. In a first step, a year-over-year material technology roadmap is established that reflects the evolution of the market-dominating (i.e., with the highest market share in automotive applications) active materials based on analyst expectations. Second, a technology roadmap for the largescale production process of automotive LIBs is set up based on the elicitation of experts from the field. Third, assuming raw material prices from 2020, material and process technology roadmaps are subsequently translated into LIB cell cost by using an existing bottom-up LIB energy and material cost estimation model, ${ }^{19}$ and a process-based cost model. ${ }^{11}$ Fourth, industry analyst reports are analyzed regarding future raw material price developments and a year-over-year assessment of their impact on cell cost is conducted. This study contributes to the field of energy research in multiple ways. First, it provides a year-over-year LIB technology roadmap based on analyst and expert expectations throughout 2030. Second, a data-driven, engineering-based LIB cost trajectory is introduced that reflects major innovations in both, battery technology and production process. Third, a cell cost analysis is presented that creates transparency on the impact of analyst estimates of future raw material price developments and allows for the assessment of individual beliefs. Fourth, raw materials that particularly put falling battery cost at risk are identified and mitigation potentials are discussed. These contributions can serve as the basis for future energy technology research, allow for a more informed, future-oriented discussion of battery cost, and support future cost reductions required in industry.

The remainder of this article is structured as follows: Section 2 presents the technology roadmap for battery technology and its production process. In Section 3, the resulting LIB cost trajectory is presented based on current raw material prices and the impact of increasing raw material prices is analyzed. Section 4 summarizes the main findings and discusses implications for research and industry, and Section 5 outlines the methods applied.

\section{Technology roadmap}

\section{Material technology roadmap}

LIBs consist of electrodes (cathodes, anodes) that accommodate lithium ions during discharge and charge operation, a separator acting as a physical barrier to prevent electric shorting, and an electrolyte to allow for ionic conduction inside the cell housing. ${ }^{20}$ Among these components, electrode materials are most expensive, together typically accounting for half of LIB cell cost, ${ }^{21}$ with their cost share expected to continuously increase throughout $2030,{ }^{8}$ and hence are focused to describe material developments in the technology roadmap. The market expectations regarding dominating material technologies for automotive applications alongside the assumptions used in this study for each year are presented in Table 1. For both electrode active materials, technological developments are expected. Regarding cathode active materials, nickel-based layered oxide cathode materials such as $\mathrm{NMC}\left(\mathrm{LiNi}_{x} \mathrm{Mn}_{y}\right.$ $\mathrm{Co}_{z} \mathrm{O}_{2}, x \geq 0.6$, often followed by a 3-digit affix that represents the molar fraction of transition metals in the formula) currently account for about $80 \%$ of the market, followed by LFP-based $\left(\mathrm{LiFePO}_{4}\right.$, lithium iron phosphate) materials with 10-20\%

Table 1 Active material technologies and related assumptions

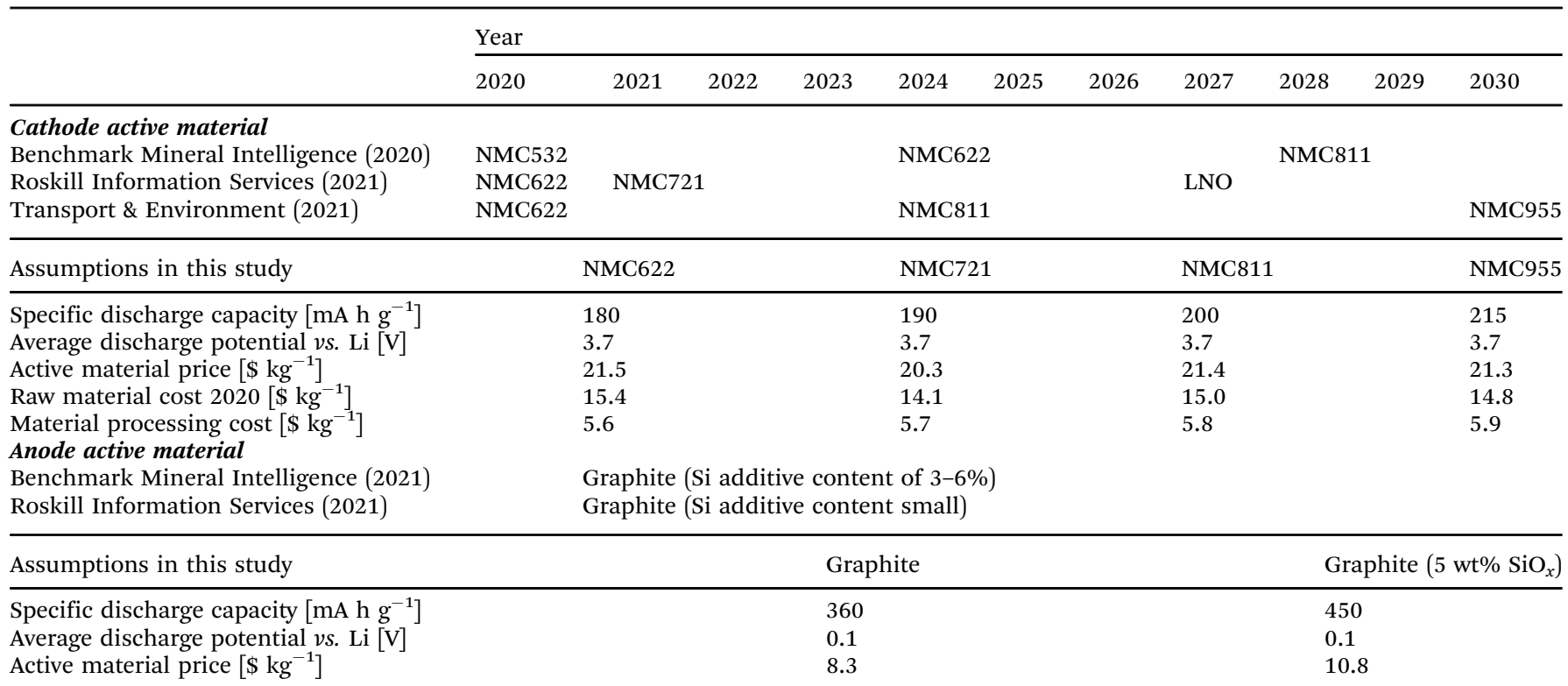


market share. ${ }^{17,22}$ For nickel-based materials, all consulted industry analysts ${ }^{16,17,22}$ expect a successive increase of the nickel content, thereby reducing the initial 2020 shares of cobalt and/or manganese. They further agree that in 2020, the molar fraction of nickel among transition metals in the dominating cathode active material did not exceed $60 \%$, and that it will increase to at least $80 \%$ in 2030 . This trend is the continuation of increasing nickel fractions in NMC materials that have been in the order of 33\% (NMC111) at the beginning of the last decade. ${ }^{21}$ The rationale behind this trend is the industry's efforts to simultaneously improve LIB energy content and cost by increasing material capacities and reducing cobalt consumption, the latter being costly and controversial in terms of sustainability and supply reliability. ${ }^{6}$ However, higher nickel contents are associated with challenges regarding battery safety (thermal runaway under abuse conditions) and performance (mainly capacity and voltage decay, impedance growth). ${ }^{21,23-25}$ The risk of thermal runaway can primarily be attributed to oxygen evolution and subsequent reactions with electrolyte and lithiated anode, which is a result of the thermodynamic instability of nickel-rich layered oxides at large lithium utilization or high temperature. ${ }^{23-25}$ Performance degradation has a variety of origins, including residual lithium compounds, $\mathrm{Ni}^{2+} / \mathrm{Li}^{+}$cationic disorder, oxygen evolution and accompanying phase transition, transition metal ion dissolution and crack formation. $^{21,23,25}$ To mitigate these challenges, development efforts focus on various approaches, including the optimization of synthesis methods, foreign-ion doping, surface coatings, single-crystal, core-shell and concentration gradient particle structures, and the application of non-flammable and oxygenscavenging electrolytes. ${ }^{21,23-25}$

Based on harmonized industry expectations, a gradual material development from NMC622 in 2020 to NMC955 in 2030 is assumed in this study. The respective materials exhibit distinct properties such as specific discharge capacity, average discharge potential $v s$. lithium, and price, being major drivers of cell energy and cost. ${ }^{13,26}$ While a similar discharge potential is assumed across the examined NMC materials, specific discharge capacity is increasing from $180 \mathrm{~mA} \mathrm{~h} \mathrm{~g}^{-1}$ for NMC622 to $215 \mathrm{~mA} \mathrm{~h} \mathrm{~g}^{-1}$ for NMC955. Further, NMC622 market prices for 2020 identified by a recent article are used $^{27}$ and with increasing nickel contents, slightly elevated NMC material processing cost (per kg) are assumed. ${ }^{21}$

Regarding anode active materials, industry analysts expect graphite to retain the highest market share compared to silicon and lithium metal throughout 2030. Gradual changes are expected regarding silicon additive content (such as silicon monoxide, $\mathrm{SiO}_{x}$, $x \approx 1$ ) that has so far been below $5 \mathrm{wt} \%{ }^{28}$ and is expected to increase in selected vehicle segments in the future. ${ }^{29,30}$ The addition of $\mathrm{SiO}_{x}$ to graphite represents a compromise between the advantages of silicon anodes, related to their high theoretical capacity ( $>4000 \mathrm{~mA} \mathrm{~h} \mathrm{~g}^{-1}$ vs. $372 \mathrm{~mA} \mathrm{~h} \mathrm{~g}^{-1}$ for graphite ${ }^{28,31}$ ), and their challenges regarding volume expansion during charging $(\sim 300 \%$ vs. $\sim 10 \%$ for graphite ${ }^{32}$ ) that imply limited cell cycle life. ${ }^{28}$ In order to represent a market-dominating anode material, graphite is assumed as active material in the first half of the decade, and a blend with $5 \mathrm{wt} \% \mathrm{SiO}_{x}$ in the second half of the decade, respectively. Accordingly, the assumed specific discharge capacity of the anode active material is expected to increase from $360 \mathrm{~mA} \mathrm{~h} \mathrm{~g}{ }^{-1}$ to $450 \mathrm{~mA} \mathrm{~h} \mathrm{~g}^{-1}$ in 2026. While the respective change in $\mathrm{SiO}_{x}$ content is resulting in an energy density advantage, it can result in cell cost increases due to higher active material prices induced by highpurity, battery-grade $\mathrm{SiO}_{x}$ prices $\left(60 \$ \mathrm{~kg}^{-1}\right.$ vs. $8.3 \$ \mathrm{~kg}^{-1}$ for graphite). ${ }^{27}$

\section{Process technology roadmap}

In addition to materials, the costs of LIBs are driven by their production process, contributing $20-40 \%$ to overall cell cost. ${ }^{11}$ This process follows three superordinate steps from electrode production, where cathode and anode active materials are applied to the current collectors, over cell assembly, where the electrode-separator-stack is produced, surrounded by a housing and filled with electrolyte, to cell conditioning, where the cell is activated, monitored and prepared for delivery. ${ }^{20} \mathrm{~A}$ detailed step-by-step description of the state-of-the-art process has been described in earlier studies. ${ }^{11,20}$ In order to establish a technology roadmap for the production process of automotive LIBs, process experts have been consulted regarding expected improvements until 2030 in the most cost-driving process steps mixing, coating, drying, stacking, formation, and aging that account for approximately two thirds of cell processing cost. ${ }^{11}$ The experts' expectations regarding innovations and parameter improvements in a large-scale automotive cell plant are summarized in Table 2. Respective changes are displayed on an annual level and are categorized according to the three superordinate steps in the cell production process.

In electrode production, fundamental innovations are anticipated that affect the process steps of mixing, coating and drying. All of the consulted experts anticipate the current batch-wise procedure, where wet electrode slurries consisting of active material, binders, conductive additives and solvents are produced in a planetary mixer, to be replaced by a continuous process until 2030. This can be achieved by the use of corotating screw mixing systems, ${ }^{33}$ that integrate material dosing, premixing, kneading, dispersion and degassing into one uninterrupted operation for the preparation of the slurry, which can be directly transferred to the coating line. ${ }^{34}$ The expectations for continuous mixing to be industrialized in a large-scale production plant for automotive cells range from 2022 to 2025 and 2023 has been calculated as the average year among experts. Regarding the solvent used to prepare the cathode slurry, all experts expect an elimination of currently used NMP ( $N$-methyl-2-pyrrolidone) either through its replacement by water, or through a solvent-free, dry coating process. NMP is a toxic and teratogen chemical compound that requires a costly and complex recovery process, and considerable drying efforts. $^{35} 2026$ has been calculated as the average year expected for NMP elimination in large-scale cathode manufacturing. The final drying step in the production of electrodes before their transfer to cell assembly, is expected to become obsolete by all experts throughout 2030, either by an integration in the continuous drying process or by the implementation of dry coating. 
Table 2 Experts' expectations regarding process innovations and improvements

\begin{tabular}{|c|c|c|c|c|c|c|c|c|c|c|c|}
\hline Innovation / Improvement & 2020 & 2021 & 2022 & 2023 & 2024 & 2025 & 2026 & 2027 & 2028 & 2029 & 2030 \\
\hline \multicolumn{12}{|l|}{ Electrode production } \\
\hline Continuous mixing & & & & $\varnothing$ & & & & & & & \\
\hline Elimination of NMP solvent (cathode) & & & & & & & $\varnothing$ & & & & \\
\hline Elimination of final drying step & & & & & & & & $\varnothing$ & & & \\
\hline Dry coating & & & & & & & & & $\varnothing$ & & \\
\hline \multicolumn{12}{|l|}{ Coating speed $\left[\mathrm{m} \mathrm{min}^{-1}\right]$} \\
\hline \multirow{3}{*}{$\begin{array}{c}\text { Pessimistic } \\
\text { Average } \emptyset \\
\text { Optimistic }\end{array}$} & 50 & 60 & 70 & 80 & 90 & 94 & 97 & 100 & 100 & 100 & 100 \\
\hline & 63 & 71 & 79 & 87 & 95 & 98 & 99 & 100 & 100 & 100 & 100 \\
\hline & 80 & 83 & 86 & 93 & 100 & 100 & 100 & 100 & 100 & 100 & 100 \\
\hline \multicolumn{12}{|l|}{ Cell assembly } \\
\hline \multicolumn{12}{|l|}{ Intelligent pick\&place / Roll-to-roll } \\
\hline \multicolumn{12}{|l|}{ Stacking speed $\left[\right.$ s sheet $\left.{ }^{-1}\right]$} \\
\hline & 1.0 & 1.0 & 1.0 & 1.0 & 1.0 & 0.7 & 0.6 & 0.5 & 0.5 & 0.5 & 0.5 \\
\hline Average $\varnothing$ & 0.8 & 0.8 & 0.7 & 0.7 & 0.7 & 0.5 & 0.5 & 0.5 & 0.4 & 0.4 & 0.4 \\
\hline & 0.6 & 0.6 & 0.5 & 0.5 & 0.5 & 0.5 & 0.5 & 0.4 & 0.4 & 0.4 & 0.3 \\
\hline \multicolumn{12}{|l|}{ Cell conditioning } \\
\hline \multicolumn{12}{|l|}{ Formation time [h] } \\
\hline & 50 & 46 & 42 & 38 & 34 & 32 & 30 & 29 & 27 & 26 & 24 \\
\hline Average $\varnothing$ & 35 & 32 & 30 & 27 & 25 & 22 & 20 & 18 & 16 & 14 & 13 \\
\hline & 10 & 9 & 9 & 8 & 8 & 7 & 6 & 6 & 5 & 5 & 4 \\
\hline \multicolumn{12}{|l|}{ Aging time [days] } \\
\hline & 14.0 & 13.3 & 12.6 & 11.9 & 11.2 & 10.5 & 9.8 & 9.1 & 8.4 & 7.7 & 7.0 \\
\hline Average $\varnothing$ & 14.0 & 13.1 & 12.1 & 11.2 & 10.2 & 9.3 & 8.3 & 7.4 & 6.4 & 5.5 & 4.5 \\
\hline & 14.0 & 12.8 & 11.6 & 10.4 & 9.2 & 8.0 & 6.8 & 5.6 & 4.4 & 3.2 & 2.0 \\
\hline \multicolumn{12}{|l|}{ Further assumptions } \\
\hline Rate of rejected cells [\%] & 15.0 & 13.6 & 12.2 & 10.8 & 9.4 & 8.0 & 6.6 & 5.2 & 3.8 & 2.4 & 1.0 \\
\hline Annual plant capacity [GWh] & 10 & 10 & 10 & 10 & 20 & 20 & 20 & 20 & 40 & 40 & 40 \\
\hline
\end{tabular}

In final drying, electrodes are typically rolled up to coils and conveyed batch-wise into vacuum ovens where residual moisture is removed before their transfer to cell assembly. ${ }^{11,20} 2027$ has been calculated as the average year for the elimination of the final drying step. All of the consulted experts anticipate wet electrode processing to be replaced by dry coating throughout 2030. In today's large-scale cell manufacturing plants, the solvent-based material slurries are applied to the collector foil through a slot-die coating device and solvents are evaporated by subsequent drying lines with a length in the order of $100 \mathrm{~m}$, thus accounting for a large share of plant investments and energy consumption. ${ }^{12,36,37}$ Several alternative, solvent-free coating technologies are in discussion that can significantly reduce drying efforts such as electrostatic spray deposition, ${ }^{38-40}$ hot rolling, ${ }^{41,42}$ magnetron sputtering, and laser deposition. ${ }^{34}$ Experts mentioned the first two technologies to be most probable for automotive cell production, which is in line with remarks in academia considering laser-based and sputtering procedures to have limited suitability for large-format electrode mass manufacturing. ${ }^{38,39,43} 2028$ has been calculated as the average year for large-scale industrialization of dry coating. In addition, incremental improvements are expected for the rollto-roll speed of the coating equipment at which electrodes are produced. The average calculated value is increasing from $63 \mathrm{~m}$ $\min ^{-1}$ in 2020 to $100 \mathrm{~m} \mathrm{~min}^{-1}$ in 2030 . In cell assembly, the innovations mentioned by the experts focus on the cost-driving process step of stacking, where the electrode-separator stack is produced. ${ }^{11}$ For large-format automotive cells, z-folding represents a state-of-the-art technology, where single cathode and anode sheets are alternatingly inserted onto a continuously fed separator lane. ${ }^{20,44}$ Experts that expressed knowledge about this process anticipated either an industrialization of highspeed single sheet stacking, where advanced pick-and-place systems are used to increase productivity, ${ }^{45}$ or the implementation of roll-to-roll technology such as coil-to-stack, which is characterized by a device that produces the cell stack from three continuously unwinding coils for cathodes, separators, and anodes. ${ }^{46}$ All experts expect reductions in the time required to produce the cell stack, and the average value is decreasing from $0.8 \mathrm{~s}^{-1}$ sheet $^{-1}$ in 2020 to $0.4 \mathrm{~s} \mathrm{sheet}^{-1}$ in 2030 . In cell conditioning, the consulted experts anticipate productivity in the cost-intensive formation and aging procedures. ${ }^{11}$ During formation, cells are charged and discharged for the first time and the solid electrolyte interphase (SEI) layer, vital for cell performance and safety, is formed. ${ }^{20,47}$ An improvement in this process step can be achieved by following advanced formation protocols that require less charge and discharge cycles and apply higher C-rates to the cell. ${ }^{48,49}$ All consulted experts expect reductions in the formation time and the average value is decreasing from $35 \mathrm{~h} \mathrm{cell}^{-1}$ in 2020 to $13 \mathrm{~h} \mathrm{cell}^{-1}$ in 2030 . In the process step of aging, cells are stored under controlled conditions in shelves or towers, and crucial parameters are monitored for a certain time interval in order to rate cell quality before final delivery to the customer. ${ }^{50}$ The process step is reported to require up to three weeks, to occupy large areas in production facilities, and hence to account for significant 


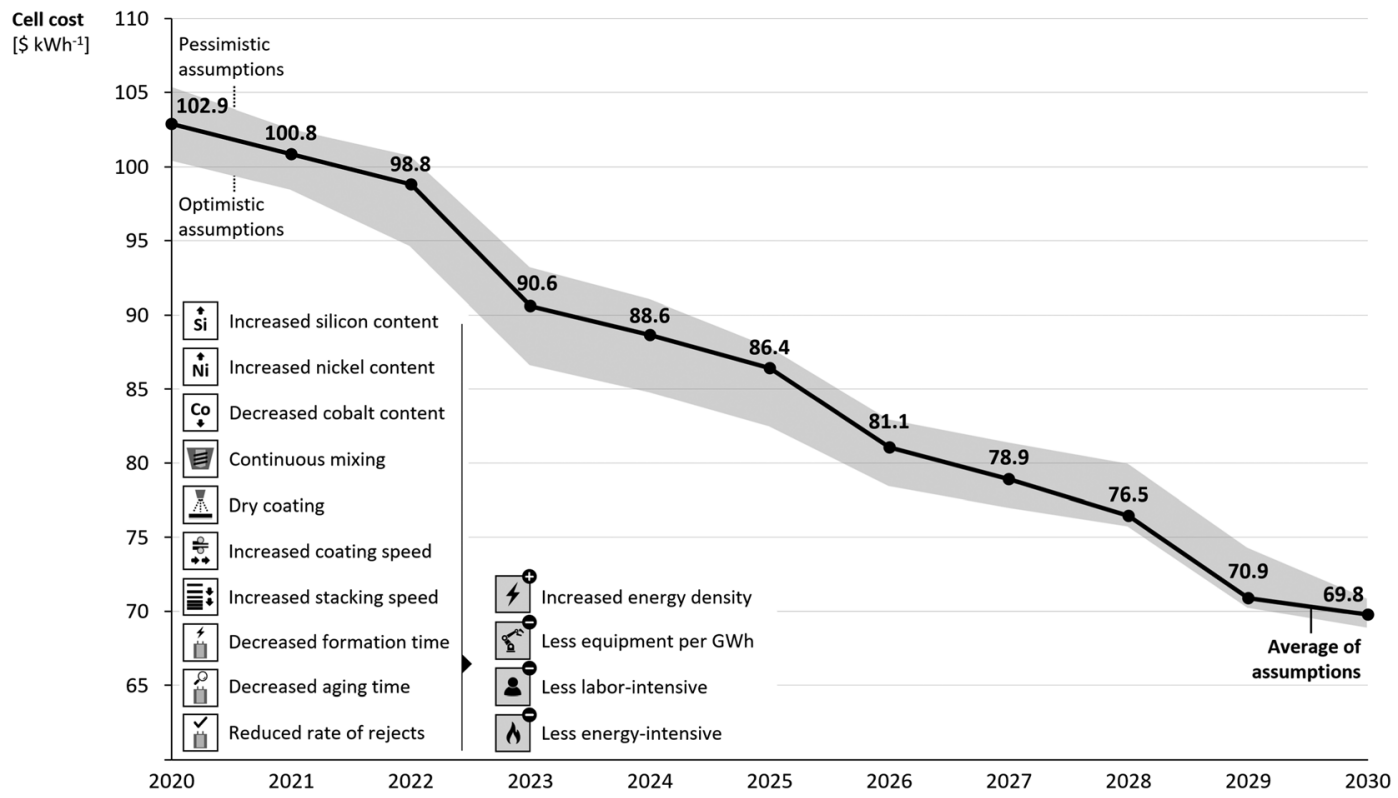

Fig. 1 Cell cost trajectory from 2020 to 2030 based on the presented material and process technology roadmap under raw material prices 2020 .

investments. $^{20,36,48}$ Experts expect a decline in aging times induced by an earlier reliable prediction of cell performance due to more accumulated data and more sophisticated analysis methods, resulting in a decrease from 14 days cell $^{-1}$ in 2020 to 4.5 days cell $^{-1}$ in 2030 on average. Further, based on expert statements, it is assumed that the rate of rejected cells declines from 15 to $1 \%$, and the annual plant production capacity increases from 10 to $40 \mathrm{GW}$ h in the period between 2020 and 2030.

\section{Results and discussion}

\section{Cell cost development at constant raw material prices}

For raw material price assumptions of 2020, the described technology roadmap and an automotive pouch cell format ${ }^{11}$ with a cathode thickness of $80 \mu \mathrm{m}$, resulting year-over-year cell cost estimates from 2020 to 2030 derived from the bottom-up models to estimate cell material and processing cost, are presented in Fig. 1. Based on the average of assumptions presented in Table 2, calculated cell cost decline from 102.9 $\mathrm{S} \mathrm{kW} \mathrm{h}^{-1}$ in 2020 (100.4 to $105.3 \mathrm{~S} \mathrm{~kW} \mathrm{~h}^{-1}$ based on optimistic assumptions, and pessimistic assumptions, respectively) to $69.8 \mathrm{~S} \mathrm{~kW} \mathrm{~h}^{-1}$ in 2030 (68.8 to $70.8 \mathrm{~S} \mathrm{~kW} \mathrm{~h}^{-1}$ ), representing a cell cost decline of $33.1 \mathrm{~S} \mathrm{~kW} \mathrm{~h}^{-1}$ in this time period.

This reduction can be attributed to the effects of technological innovations on both, cell material and processing costs. Since a fixed automotive pouch cell format is assumed throughout the time period, the change to higher specific capacities in cathode (NMC955) and anode $\left(\mathrm{SiO}_{x}\right.$ content of 5\%) materials results in an increase of cell energy density of $21 \%$. This has a threefold effect on cell cost per amount of energy produced. First, this results in lower active material cost, second, in lower cost for inactive materials, and third, in lower cell processing cost since more energy output can be produced with the same production equipment and associated labor and energy consumption. Processing cost are further reduced during this period by the industrialization of the advanced process technologies continuous mixing and dry coating, the elimination of NMP solvents and the final drying step, reduced cycle times in the cost-driving process steps of stacking, formation and aging, and a reduction in the rate of rejected cells. This is due to the fact that, per amount of cell energy produced, lower investments for machinery and equipment, less labor hours, less electricity and lower production footprints are required. In total, between 2020 and 2030, average reductions of 15\% for material cost are calculated and $50 \%$ for labor cost, $58 \%$ for plant depreciation, $39 \%$ for energy cost, and $74 \%$ for material scrap, respectively.

\section{The impact of increasing raw material prices on cell cost development}

In order to evaluate the impact of tightening raw material markets on future cell cost development, raw material prices are annually increased and the effect on cell cost based on the technology roadmap with average assumptions is calculated. In Fig. 2a-f, the results for different levels of price increase of the raw materials lithium, nickel, manganese, cobalt, and graphite from moderate (up to $2 \%$ per annum) to substantial (between 18 to $20 \%$ p.a.) are displayed by shaded segments from dark blue to light blue.

Fig. 2a presents the effect of the combined price increase of all five analyzed raw materials on cell cost. When examining the size of the blue segments, the extent of the cell cost sensitivity to raw material prices becomes apparent ( $2 \%$ p.a. combined raw material price increase results in a cell cost delta of $+8.3 \%$ in 2030). This effect is composed of the cell cost sensitivity to single raw material prices depicted in Fig. $2 \mathrm{~b}-\mathrm{f}$, where all other raw material prices are assumed to remain constant. A closer analysis shows that cell costs are most and increasingly 

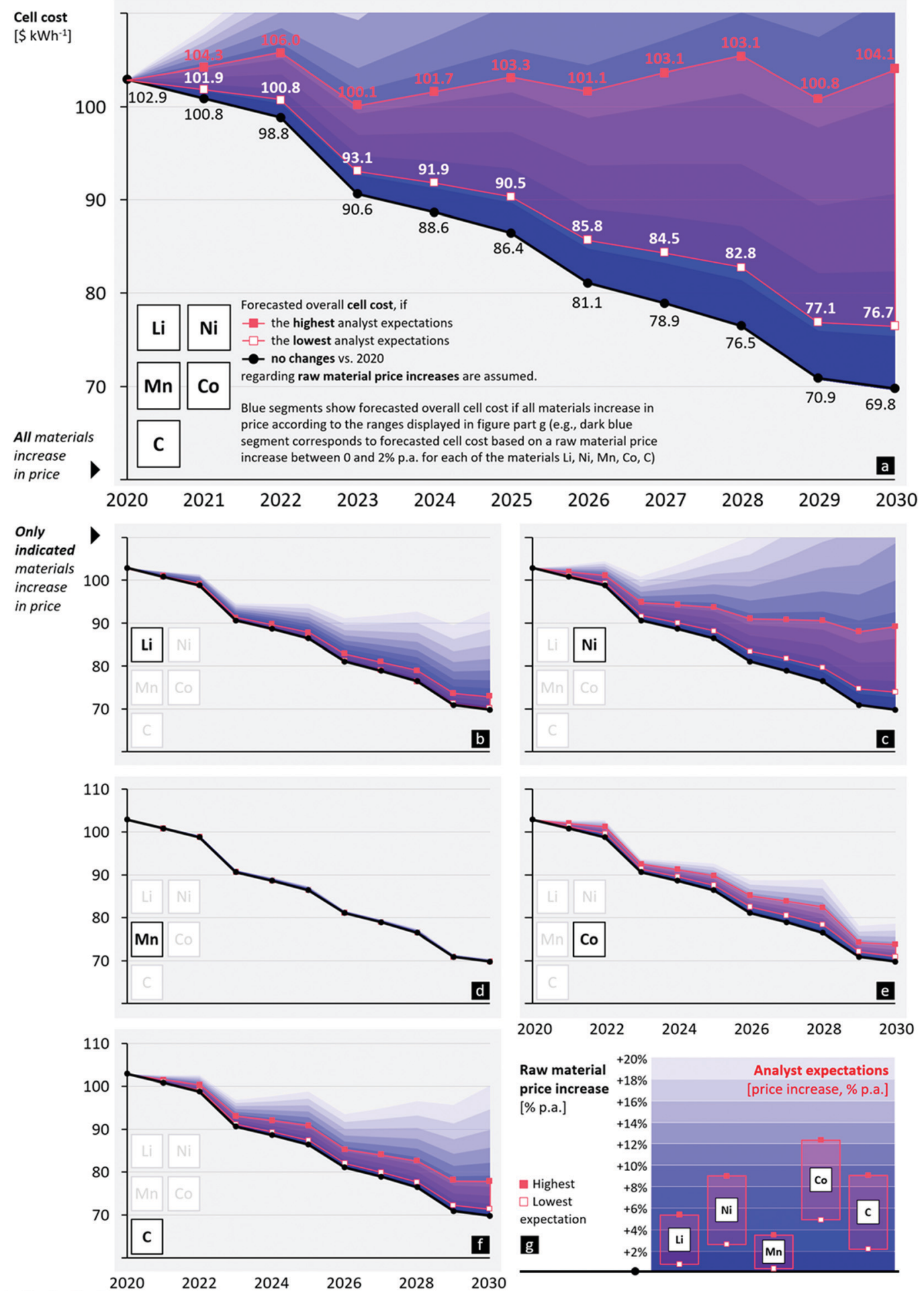

Fig. 2 Impact of increasing raw material prices on the cell cost development throughout 2030 for all materials combined (a), lithium (b), nickel (c), manganese (d), cobalt (e), graphite (f), alongside analyst expectations for raw material price developments (g).

sensitive to variations in nickel prices $(2 \%$ p.a. increase of raw material price results in cell cost delta of $+4.5 \%$ in 2030 ). While further significant effects result from increases in graphite $(+1.8 \%)$ and lithium prices $(+1.4 \%)$, cell cost are less and decreasingly sensitive to cobalt price variations $(+0.5 \%)$, and manganese price increases show only a marginal effect on cell cost $(+0.03 \%)$. These findings are a logical consequence of successively replacing cobalt and manganese with nickel when 
moving from NMC622 to NMC955 in the presented technology roadmap. While all of the respective raw materials are considered to represent bottlenecks or involve significant supply risks in the future, ${ }^{51-54}$ a literature review of analyst reports revealed differentiated expectations regarding material-specific price developments (see ESI $\dagger$ for related sources). The results of this review are displayed in Fig. $2 \mathrm{~g}$ as intervals that range from the lowest (signified by hollow red polygon) to the highest analyst expectation (signified by solid red polygon) identified in literature. Prices are expected to annually increase between 4.8 to $12.4 \%$ for cobalt, between 2.2 to $9.0 \%$ for graphite, between 2.6 to $8.9 \%$ for nickel, between 0.6 to $5.6 \%$ for lithium, and between 0.3 to $3.6 \%$ for manganese, respectively. The resulting cell cost impact of these price expectations are displayed as red segments in Fig. 2a-f, of which the upper bound (solid red polygons) corresponds to the maximum expected price increase, and the lower bound to the minimum (hollow red polygons), respectively. The combined impact of materialspecific price increases on cell cost in 2030 shown in Fig. 2a ranges from +6.9 to $+34.3 \mathrm{SW} \mathrm{h}^{-1}$, meaning that cell cost reductions from technological innovations could be significantly slowed down or, under the most pessimistic raw material price expectations, fully vanish in 2030. When comparing the cost effect related to analyst expectations for single raw materials shown in Fig. 2b-f, the highest cell cost impact can be attributed to the nickel price $\left(+4.2\right.$ to $+19.3 \mathrm{~S} \mathrm{~kW} \mathrm{~h}^{-1}$ in 2030), followed by graphite $\left(+1.4\right.$ to $\left.+8.0 \mathrm{~S} \mathrm{~kW} \mathrm{~h}^{-1}\right)$, cobalt $(+1.0$ to $\left.+3.7 \mathrm{~S} \mathrm{~kW} \mathrm{~h}^{-1}\right)$, lithium $\left(+0.3\right.$ to $\left.+3.2 \mathrm{SW} \mathrm{h}^{-1}\right)$, and manganese $\left(<0.1 \mathrm{~kW} \mathrm{~h} \mathrm{~h}^{-1}\right)$, exposing battery companies, and further downstream, industries offering battery-powered products, to a significant nickel price risk.

\section{Conclusion}

The deduction of the material technology roadmap revealed that, throughout this decade, nickel-rich LIB chemistries are expected to remain in a dominant market position in automotive applications and that increasing their nickel content is considered a major development path to increase energy density and reduce cost. The establishment of the process technology roadmap showed that experts anticipate significant improvements in large-scale LIB production by continuous mixing in the first half, and the elimination of NMP solvents, the elimination of the final drying step, and the industrialization of dry coating in the second half of the decade. Experts further expect increasing efficiencies for the process steps of stacking, formation, and aging. Both, improvements in cell material composition and production process translated into a cell cost reduction from above $100 \mathrm{~S} \mathrm{~kW} \mathrm{~h}^{-1}$ in 2020 to around $70 \mathrm{~S} \mathrm{~kW} \mathrm{~h}^{-1}$ in 2030, given that raw material prices remain at their current level. However, the combined analysis of cell cost sensitivity and analyst expectations regarding raw material price increases showed that cell cost declines might significantly flatten or, under the highest expected price increases, fully vanish by tightening raw material markets. Nickel in particular has been shown to represent a high price risk for cell cost with the potential to increase 2030 cell cost by up to $20 \mathrm{SW} \mathrm{h} \mathrm{h}^{-1}$. This adds to an already elevated environmental impact of nickel-containing batteries, ranging from greenhouse gas and $\mathrm{SO}_{2}$ emissions, soil contamination, to biodiversity loss, associated with nickel mining and downstream refining, ${ }^{55}$ confronting the industry with a twofold challenge: Providing sufficient nickel supply to support an economically feasible mobility transition while rendering this transition ecologically sound. Regarding the first aspect, industry measures should aim to increase nickel supply by the global exploration of new sources available for battery production. These sources can include new mining activities such as greenfield projects (e.g., Central Musgrave project, Australia $\left.{ }^{56}\right)$ and brownfield expansions (e.g., Sorowako, Indonesia ${ }^{16}$ ) mainly for laterite ores, the conversion of lower-grade intermediates (e.g., nickel pig iron, nickel matte ${ }^{57}$ ) to battery-grade nickel, the development of untapped geological nickel resources (e.g., manganese nodules from deep sea mining ${ }^{58,59}$, and the full use of the recycling potential from discarded nickel-containing products. ${ }^{60} \mathrm{How}^{-}$ ever, regarding the second aspect, for all of these measures substantial advances are indispensable for these activities to become environmentally benign, ${ }^{61,62}$ a crucial and urgent task for both academia and industry. In order to mitigate both, nickel-related price and environmental risks, cell manufacturers and automotive producers need to jointly explore alternative, less nickel-reliant development paths. For less range-sensitive applications, these include lithium iron phosphate (e.g., LFP, LMFP) and manganese-rich (e.g., NCM307) chemistries. For more range-sensitive applications, development efforts should focus on overcoming the durability and safety challenges that currently impede the widespread adoption of alternative chemistries promising high energy density, such as high-voltage spinel oxide chemistries (e.g., LNMO with molar nickel share among transition metals $\leq 50 \%$; to date suffering from rapid capacity decay due to electrolyte degradation ${ }^{63-65}$ ) and lithium and manganese-rich chemistries (e.g., $\mathrm{Li}_{a} \mathrm{Ni}_{x} \mathrm{Mn}_{y} \mathrm{Co}_{z} \mathrm{O}_{2}, a \geq 1, x \leq 0.2, y \geq 0.5$; suffering from voltage and capacity fade, and voltage hysteresis due to oxygen release and transition metal migration triggered by oxygen redox activity $\left.{ }^{6,65,66}\right)$. Further, respective companies should evaluate options for vertical integration of sustainable nickel mining and refining to reduce price risks at global markets, and to gain competitive advantages by a reduced environmental production footprint and an elimination of margins for intermediate nickel products.

\section{Methods}

\section{Definition of material and process technology roadmap}

In order to identify a material technology roadmap that reflects the mainstream development path for automotive applications, a literature review was conducted on the expectations of recent analyst sources ${ }^{16,17,22}$ that are frequently cited in official reports and whose market intelligence has been publicly available. 
Table 3 List of consulted experts to derive the technology roadmap

Expert Role \& affiliation (at the time of interview)

Prof. Dr-Ing. Arno Kwade

Dr André Mecklenburg

Hannes W. Weinmann

Dr-Ing. Heiner Heimes
Director, Institute of Particle Technology, Technische Universität Braunschweig

Vice President Process Engineering, Northvolt Zwei GmbH

Research Associate, Institute of Production Science, Karlsruhe Institute of Technology

Chief Engineer, Chair of Production Engineering E-Mobility Components, RWTH Aachen University
These have been analyzed and regarding cathode active materials, for each available year between 2020 and 2030 the material with the highest anticipated market share has been displayed in Table 1 . While the respective sources agree on an increasing nickel content in the cathode active material, slight variations exist in exact composition and time of market-dominance and have been harmonized by the authors of this study. Further, analyst sources agree that graphite will remain the most widely used anode active material throughout the decade and that silicon additive contents will increase, ${ }^{30,67,68}$ yet detailed annual forecasts regarding silicon additive content are not available. Hence, anode active materials have been defined based on the available information and two interviews with material experts. In order to derive a process technology roadmap, where expectations regarding time of industrialization are not publicly available, four expert interviews have been conducted in the time between September 2020 and February 2021. The list of consulted experts is presented in Table 3. Experts have been selected based on their academic record in the field of battery manufacturing and their industry expertise on international process-related innovation activities. All of the consulted experts have expressed to provide estimates to the best of their knowledge and without pursuing particular interests of their institutions.

Each interview was conducted as a video call and lasted approximately ninety minutes. In advance of each interview, an information document has been sent to each expert consisting of a short description of the research topic, the results of a literature review on battery cost forecasting, the interview process, and the format targeted to structure the technology roadmap later used as the basis for the cost estimation. All interviews were based on the assumption of a common large-format pouch cell dedicated to automotive applications (e.g., see ref. 69) and a large-scale manufacturing process with an annual production capacity of at least $10 \mathrm{GW} \mathrm{h}$, and have been conducted in two sequential steps. First, experts were asked regarding their expectations of new process technologies along the value chain in a cell plant from electrode production to cell conditioning that are relevant for cell cost. Second, experts allocated these innovations to specific years where they expect largescale industrialization for automotive applications. In addition, the expected development of production parameters of the cost-driving process steps ${ }^{11}$ electrode coating, cell stacking, formation and aging were discussed and documented. After the completion of the interview process, experts received their individual technology roadmap in written form and were given the opportunity to provide feedback and to adjust their expectations. The individual expectations of experts are not published due to confidentiality reasons. Based on the individual technology roadmaps, three scenarios have been created that vary in their process-related assumptions. An optimistic scenario, characterized by the earliest industrialization of innovations and the most optimistic parameter improvements expected by the interviewees, a pessimistic scenario characterized by the most pessimistic assumptions, and an average scenario defined by the arithmetic mean of the expected years for industrialization and of the assumed parameters among all expert replies.

\section{Cell cost modeling and raw material prices}

The three scenarios obtained from the elicitation of experts have been separated into annually varying parameter sets that serve as inputs for the estimation of cell cost in two existing cost models. Material-related parameters have been fed into a bottom-up energy and cost estimation model to calculate cell energy and cell material cost. ${ }^{19}$ These interim results in turn serve as inputs for a processbased cost model ${ }^{11}$ that reflects the cell production process from material mixing to the finished battery cell and adds processing cost consisting of depreciation for machinery and building, and costs related to material scrap, labor, energy, maintenance, and overhead. The model architecture of both models is described in the respective publications. For each scenario, the annual cost estimates are connected to a cost trajectory from 2020 to 2030. For the cost trajectory at constant raw material prices depicted in Fig. 1, raw material prices for 2020 identified in a recent study ${ }^{27}$ have been assumed (lithium hydroxide $\mathrm{LiOH} \cdot \mathrm{H}_{2} \mathrm{O}(56.5 \%): 7.34 \$ \mathrm{~kg}^{-1}$, nickel sulfate $\mathrm{NiSO}_{4}\left(\mathrm{H}_{2} \mathrm{O}\right)_{6}: 4.27 \$ \mathrm{~kg}^{-1}$, manganese sulfate $\mathrm{MnSO}_{4} \cdot \mathrm{H}_{2} \mathrm{O}$ : $0.89 \mathrm{\$} \mathrm{kg}^{-1}$, cobalt sulfate $\mathrm{CoSO}_{4} \cdot 7 \mathrm{H}_{2} \mathrm{O}: 8.41 \mathrm{~S} \mathrm{~kg}^{-1}$, and nature graphite (high-end): $8.26 \mathrm{~kg}^{-1}$ ). These values have been used as base prices for the sensitivity analysis depicted in Fig. 2. Regarding expectations of raw material price increases, a literature review has been conducted in relevant analyst sources that provided price forecasts for the respective raw materials (see ESI $\dagger$ for values and related sources).

\section{Conflicts of interest}

There are no conflicts to declare.

\section{References}

1 S. S. Sharma and A. Manthiram, Towards more environmentally and socially responsible batteries, Energy Environ. Sci., 2020, 13, 4087-4097.

2 I. Staffell, et al., The role of hydrogen and fuel cells in the global energy system, Energy Environ. Sci., 2019, 12, 463-491.

3 L. Mauler, L. Dahrendorf, F. Duffner, M. Winter and J. Leker, Cost-effective technology choice in a decarbonized and diversified long-haul truck transportation sector: A U.S. case study, J. Energy Storage, 2022, 46, 103891. 
4 M. Beuse, B. Steffen and T. S. Schmidt, Projecting the competition between energy-storage technologies in the electricity sector, Joule, 2020, 4, 2162-2184.

5 F. Duffner, M. Wentker, M. Greenwood and J. Leker, Battery cost modeling: A review and directions for future research, Renewable Sustainable Energy Rev., 2020, 127, 109872.

6 R. Schmuch, R. Wagner, G. Hörpel, T. Placke and M. Winter, Performance and cost of materials for lithium-based rechargeable automotive batteries, Nat. Energy, 2018, 3, 267-278.

7 O. Schmidt, A. Hawkes, A. Gambhir and I. Staffell, The future cost of electrical energy storage based on experience rates, Nat. Energy, 2017, 2, 17110.

8 I.-Y. L. Hsieh, M. S. Pan, Y.-M. Chiang and W. H. Green, Learning only buys you so much: Practical limits on battery price reduction, Appl. Energy, 2019, 239, 218-224.

9 Bloomberg New Energy Finance, Battery Pack Prices Cited Below \$100/kWh for the First Time in 2020, While Market Average Sits at $\$ 137 / \mathrm{kWh}, 2020$, https:/about.bnef.com/ blog/battery-pack-prices-cited-below-100-kwh-for-the-firsttime-in-2020-while-market-average-sits-at-137-kwh/.

10 L. Mauler, F. Duffner, W. G. Zeier and J. Leker, Battery cost forecasting: A review of methods and results with an outlook to 2050, Energy Environ. Sci., 2021, 14, 4712-4739.

11 F. Duffner, L. Mauler, M. Wentker, J. Leker and M. Winter, Large-scale automotive battery cell manufacturing: Analyzing strategic and operational effects on manufacturing costs, Int. J. Prod. Econ., 2021, 232, 107982.

12 L. Mauler, F. Duffner and J. Leker, Economies of scale in battery cell manufacturing: The impact of material and process innovations, Appl. Energy, 2021, 286, 116499.

13 F. Duffner, et al., Post-lithium-ion battery cell production and its compatibility with lithium-ion cell production infrastructure, Nat. Energy, 2021, 6, 123-134.

14 Goldman Sachs, Electric automakers must brace for rising battery materials costs, Goldman says, 2021, https://www.cnbc. com/2021/03/24/goldman-electric-cars-face-rising-battery-lithiumnickel-cobalt-costs.html.

15 Benchmark Mineral Intelligence, Lithium ion battery cell prices fall to $\$ 110 / \mathrm{kWh}$, but raw material risk looms large, 2020, https:// www.benchmarkminerals.com/membership/lithium-ion-batterycell-prices-fall-to-110-kwh-but-raw-material-risk-looms-large-2/.

16 Roskill Information Services, Study on future demand and supply security of nickel for electric vehicle batteries, 2021, https://publica tions.jrc.ec.europa.eu/repository/handle/JRC123439.

17 Benchmark Mineral Intelligence, Lithium-ion battery supply chain technology development and investment opportunities, 2020, https://energy.stanford.edu/events/energy-seminar-vivas-kumar.

18 M. S. Ziegler and J. E. Trancik, Re-examining rates of lithium-ion battery technology improvement and cost decline, Energy Environ. Sci., 2021, 14, 1635-1651.

19 M. Wentker, M. Greenwood and J. Leker, A bottom-up approach to lithium-ion battery cost modeling with a focus on cathode active materials, Energies, 2019, 12, 504.

20 A. Kwade, et al., Current status and challenges for automotive battery production technologies, Nat. Energy, 2018, 3, 290-300.
21 W. Li, E. M. Erickson and A. Manthiram, High-nickel layered oxide cathodes for lithium-based automotive batteries, Nat. Energy, 2020, 5, 26-34.

22 Transport \& Environment, From dirty oil to clean batteries, 2021, https://www.transportenvironment.org/sites/te/files/publi cations/2021_02_Battery_raw_materials_report_final.pdf.

23 S. S. Zhang, Problems and their origins of Ni-rich layered oxide cathode materials, Energy Storage Mater., 2020, 24, 247-254.

$24 \mathrm{~J}$. Hou, et al., Unlocking the self-supported thermal runaway of high-energy lithium-ion batteries, Energy Storage Mater., 2021, 39, 395-402.

25 M. Jiang, D. L. Danilov, R. Eichel and P. H. L. Notten, A review of degradation mechanisms and recent achievements for Ni-rich cathode-based Li-ion batteries, Adv. Energy Mater., 2021, 11, 2103005.

26 D. Andre, et al., Future generations of cathode materials: An automotive industry perspective, J. Mater. Chem. A, 2015, 3, 6709-6732.

27 M. Greenwood, M. Wentker and J. Leker, A bottom-up performance and cost assessment of lithium-ion battery pouch cells utilizing nickel-rich cathode active materials and silicon-graphite composite anodes, J. Power Sources, 2021, 9, 100055.

$28 \mathrm{~J}$. W. Choi and D. Aurbach, Promise and reality of postlithium-ion batteries with high energy densities, Nat. Rev. Mater., 2016, 1, 16013.

29 Benchmark Mineral Intelligence, Sila Nanotechnologies' half a billion dollar raise puts anodes at the center of battery and EV dialogue, 2021, https://www.benchmarkminerals.com/ membership/sila-nanotechnologies-half-a-billion-dollar-raise-putsanodes-at-the-centre-of-battery-and-ev-dialogue/.

30 Roskill Information Services, Silicon: Porsche looking at silicon in EV battery anode, 2021, https://roskill.com/news/ silicon-porsche-looking-at-silicon-in-ev-battery-anode/.

$31 \mathrm{~W}$. Zuo, et al., Li-rich cathodes for rechargeable Li-based batteries: reaction mechanisms and advanced characterization techniques, Energy Environ. Sci., 2020, 13, 4450-4497.

32 T. Placke, R. Kloepsch, S. Dühnen and M. Winter, Lithium ion, lithium metal, and alternative rechargeable battery technologies: The odyssey for high energy density, J. Solid State Electrochem., 2017, 21, 1939-1964.

33 H. Dreger, M. Huelsebrock, L. Froboese and A. Kwade, Method development for quality control of suspensions for lithium-ion battery electrodes, Ind. Eng. Chem. Res., 2017, 56, 2466-2474.

34 E. Kendrick, Advancements in manufacturing, in Future Lithiumion Batteries, ed. A. Eftekhari, Royal Society of Chemistry, 2019, pp. 262-289, DOI: 10.1039/9781788016124.

35 D. Bresser, D. Buchholz, A. Moretti, A. Varzi and S. Passerini, Alternative binders for sustainable electrochemical energy storage - the transition to aqueous electrode processing and bioderived polymers, Energy Environ. Sci., 2018, 11, 3096-3127.

36 H. Heimes et al., Lithium-ion battery cell production process, 2018.

37 B. G. Westphal and A. Kwade, Critical electrode properties and drying conditions causing component segregation in graphitic anodes for lithium-ion batteries, J. Energy Storage, 2018, 18, 509-517. 
38 M. Al-Shroofy, et al., Solvent-free dry powder coating process for low-cost manufacturing of LiNi1/3Mn1/3Co1/3O2 cathodes in lithium-ion batteries, J. Power Sources, 2017, 352, 187-193.

39 B. Ludwig, Z. Zheng, W. Shou, Y. Wang and H. Pan, Solventfree manufacturing of electrodes for lithium-ion batteries, Sci. Rep., 2016, 6, 23150.

40 G. Schälicke, et al., Solvent-free manufacturing of electrodes for lithium-ion batteries via electrostatic coating, Energy Technol., 2020, 8, 1900309.

41 S. Tschöcke, From powder to the roll: dry-coated battery electrodes, 2015, https:/www.iws.fraunhofer.de/content/dam/ iws/en/documents/publications/annual_report_articles/2015/JBIWS-2015-en-S70-71.pdf.

42 H. Duong, J. Shin and Y. Yudi, Dry electrode coating technology, in 48th Power Sources Conference, 2018, pp. 34-37.

43 D.-W. Park, N. A. Cañas, N. Wagner and K. A. Friedrich, Novel solvent-free direct coating process for battery electrodes and their electrochemical performance, J. Power Sources, 2016, 306, 758-763.

44 A. Schilling, J. Schmitt, F. Dietrich and K. Dröder, Analyzing bending stresses on lithium-ion battery cathodes induced by the assembly process, Energy Technol., 2016, 4, 1502-1508.

$45 \mathrm{M}$. Baumeister and J. Fleischer, Integrated cut and place module for high productive manufacturing of lithium-ion cells, CIRP Ann., 2014, 63, 5-8.

46 R. Diehm, et al., Edge formation in high-speed intermittent slot-die coating of disruptively stacked thick battery electrodes, Energy Technol., 2020, 8, 1900137.

47 M. Winter, The solid electrolyte interphase - The most important and the least understood solid electrolyte in rechargeable $\mathrm{Li}$ batteries, Z. Phys. Chem., 2009, 223, 1395-1406.

48 D. L. Wood, J. Li and C. Daniel, Prospects for reducing the processing cost of lithium ion batteries, J. Power Sources, 2015, 275, 234-242.

49 C. Mao, et al., Balancing formation time and electrochemical performance of high energy lithium-ion batteries, J. Power Sources, 2018, 402, 107-115.

50 M. Keppeler, H.-Y. Tran and W. Braunwarth, The role of pilot-lines in bridging the gap between fundamental research and industrial production for lithium ion battery cells relevant to sustainable electromobility - A review, Energy Technol., 2021, 9, 2100132.

51 T. M. Gür, Review of electrical energy storage technologies, materials and systems: challenges and prospects for largescale grid storage, Energy Environ. Sci., 2018, 11, 2696-2767.

52 E. A. Olivetti, G. Ceder, G. G. Gaustad and X. Fu, Lithium-ion battery supply chain considerations: Analysis of potential bottlenecks in critical metals, Joule, 2017, 1, 229-243.

53 B. Ballinger, et al., The vulnerability of electric vehicle deployment to critical mineral supply, Appl. Energy, 2019, 255, 113844.

54 A. Valero, A. Valero, G. Calvo and A. Ortego, Material bottlenecks in the future development of green technologies, Renewable Sustainable Energy Rev., 2018, 93, 178-200.
55 J. B. Dunn, L. Gaines, J. C. Kelly, C. James and K. G. Gallagher, The significance of Li-ion batteries in electric vehicle life-cycle energy and emissions and recycling's role in its reduction, Energy Environ. Sci., 2015, 8, 158-168.

56 Mining.com, World's top 10 nickel projects, 2021, https://www. mining.com/featured-article/ranked-worlds-top-10-nickel-projects/.

57 S\&P Global, Nickel pig iron-matte conversion could be a game changer for the battery industry, 2021, https://www. spglobal.com/platts/en/market-insights/podcasts/platts-futureenergy/041321-nickel-battery-tsingshan-ev-pig-iron-matte-energytransition.

58 T. Abramovski, V. P. Stefanova, R. Causse and A. Romanchuk, Technologies for the processing of polymetallic nodules from Clarion Clipperton Zone in the Pacific Ocean, J. Chem. Technol. Metall., 2017, 52, 258-269.

59 J. R. Hein, A. Koschinsky and T. Kuhn, Deep-ocean polymetallic nodules as a resource for critical materials, Nat. Rev. Earth Environ., 2020, 1, 158-169.

$60 \mathrm{C} . \mathrm{Xu}$, et al., Future material demand for automotive lithium-based batteries, Commun. Mater., 2020, 1, 99.

61 W. Wei, P. B. Samuelsson, A. Tilliander, R. Gyllenram and P. G. Jönsson, Energy consumption and greenhouse gas emissions of nickel products, Energies, 2020, 13, 5664.

62 G. Bartzas, P. E. Tsakiridis and K. Komnitsas, Nickel industry: Heavy metal(loid)s contamination - sources, environmental impacts and recent advances on waste valorization, Curr. Opin. Environ. Sci. Heal., 2021, 21, 100253.

63 S. Deng, et al., New insight into atomic-scale engineering of electrode surface for long-life and safe high voltage lithium ion cathodes, Nano Energy, 2017, 38, 19-27.

$64 \mathrm{H}$. Xu, et al., Overcoming the challenges of $5 \mathrm{~V}$ spinel LiNi0.5Mn1.5O4 cathodes with solid polymer electrolytes, ACS Energy Lett., 2019, 4, 2871-2886.

65 S. Sharifi-Asl, J. Lu, K. Amine and R. Shahbazian-Yassar, Oxygen release degradation in Li-ion battery cathode materials: Mechanisms and mitigating approaches, Adv. Energy Mater., 2019, 9, 1900551.

66 P. Vanaphuti, et al., Enhanced electrochemical performance of the lithium-manganese-rich cathode for Li-ion batteries with $\mathrm{Na}$ and $\mathrm{F}$ codoping, ACS Appl. Mater. Interfaces, 2019, 11, 37842-37849.

67 Investing News, Graphite Outlook 2021: Demand from Battery Segment to Grow, 2021, https://investingnews.com/ daily/resource-investing/battery-metals-investing/graphiteinvesting/graphite-outlook/.

68 Benchmark Mineral Intelligence, Tesla's silicon battery anode tease stands out, but what is the commercial reality? 2020, https:/www.benchmarkminerals.com/membership/teslassilicon-battery-anode-tease-stands-out-but-what-is-the-commercialreality/.

69 F. Duffner, O. Krätzig and J. Leker, Battery plant location considering the balance between knowledge and cost: A comparative study of the EU-28 countries, J. Cleaner Prod., 2020, 264, 121428. 